\title{
The New Development Economics
}

\author{
JOSEPH E. STIGLITZ* \\ Princeton University, New Jersey
}

\begin{abstract}
Summary. - The theory of rural organization based on rational peasants in environments where information is imperfect and costly provides a simple explanation for a wide variety of phenomena in LDCs. It provides insights into both why sharecropping is so widespread and why it takes on the particular forms that it does; it provides an explanation of the interlinkage of credit and land markets, and of cost sharing. The paper argues that this theory provides a better explanation of these phenomena than do the competing theories. This theory can be viewed as an important application of a more general paradigm, the "Imperfect Information Paradigm," which has been useful in explaining economic phenonema under a wide variety of settings: under competition, oligopoly, and monopoly; in labor markets. capital markets, in insurance markets. and product markets; and in developed and less developed countries.
\end{abstract}

\section{INTRODUCTION}

For the past 15 years, I have been attempting to construct a consistent view of less developed economies and the development process, to identify in what ways they are similar and in what ways (and why) they are different from more developed economies. 'I cannot present even a summary of these views here. What I have been asked to do is to present one piece of that perspective, that relating to the organization of the rural sector, and to explain why I (or someone else) should "believe" these theories, or at least, why they are more plausible than several widely discussed alternative theories.

There are five eentral tencts of my approach:

1. Individuals (including peasants in the rural sectors of LDCs) are rational, that is, they act in a (reasonably) consistent manner, one which adapts to changes in circumstances.

2. Information is costly. This has numerous important implications: individuals do not acquire perfect information, and hence their behavior may differ markedly from what it would have been if they had perfect information. When individuals engage in a trade (buying labor services, extending credit, renting land or bullocks), there is imperfect information concerning the items to be traded; thus, transactions which would be desirable in the presence of perfect information may not occur. Similarly, certain contracts, e.g. performing certain services at a certain standard, may not be feasible, especially if it is costly to ascertain, ex post, whether or how well those services have been performed.

3. Institutions adapt to reflect these informa- tion (and other transaction) costs. Thus, institutions are not to be taken as exogenous, but are endogenous, and changes in the environment may lead, with a lag, to changes in institutional structure.

4. The fact that individuals are rational and that institutions are adaptable does not, however, imply that the economy is (Pareto) efficient. The efficiency of market economies obtains only under the peculiar set of circumstances explored by Arrow and Debreu. These include a complete set of markets and perfect information, assumptions which, if questionable in more developed economies, are clearly irrelevant in LDCs. With imperfect information and incomplete markets, the economy is almost always constrained Pareto inefficient, i.e., there exists a set of taxes and subsidies which can make everyone better off (Sec Greenwald and Stiglitz, forthcoming).

5. This implies that there is a potential role for the government. That is, the government could effect a Pareto improvement if (i) it had sufficient knowledge of the structure of the economy; (ii) those responsible for implementing government policy had at least as much information as those in the private sector; (iii) those responsible for designing and implementing government policy had the incentives to direct policies to effect Pareto improvements, rather than, for instance, to redistribute income (either from the poor to the rich or vice versa, or from everyone else, to

*I am indebtcd to A. Braverman and R. Sah for helpful discussions. Financial support from the National Science Foundation is gratefully acknowledged. 
themselves), often at considerable loss to national output. Informational problems, including incentive problems, are no less important in the public sector than in the private; the fact that we have studied them well in the latter does not mean that they are not present in the former. The consequence of these remarks is to make us cautious in recommending particular government actions as remedies for certain observed deficiencies in the market.

\section{THE BASIC OUTLINES OF THE THEORY OF RURAL ORGANIZATION}

In this section, I wish to outline what the general approach presented above says about the economic organization of the rural sector. There are a wide variety of institutional arrangements observed in different LDCs. One set that has been of longstanding interest to economists is sharecropping. Earlier views of sharecropping held that it was an inefficient form of economic organization: the worker received less than the value of his marginal product, and thus he had insufficient incentives to exert effort. The question was, how could such a seemingly inefficient form of economic organization have survived for so long (and why should it be such a prevalent form of economic organization at so many different places at different times?). For those who believe in even a modicum of economic rationality, some explanation had to be found.

One explanation that comes to mind is that peasants are more risk averse than landlords; if workers rented the land from the landlords, they would have to bear all of the risk. Though workers' risk aversion is undoubtedly of importance, it cannot be the entire explanation: there are alternative (and perhaps more effective) risk-sharing arrangements. In particular, in the wage system, the landlord bears all of the risk, the worker none. Any degree of risk sharing between the landlord and the worker can be attained by the worker dividing his time between working as a wage-laborer and working on his own or rented land. ${ }^{2}$

The other central part of the explanation of sharecropping is that it provides an effective incentive system in the presence of costly supervision. Since in a wage system, the worker's compensation is not directly related to his output, the landlord must spend resources to ensure that the worker actually works. In a sharecropping system, since the worker's pay depends directly on his output, he has some incentives to work. The incentives may not be as strong as they would if he owned the land (since he receives, say, only half the product); but that is not the relevant alternative. Sharecropping thus represents a compromise between the rental system, in which incentives are "correct" but all the risk is borne by the worker, and the wage system, in which the landlord who is in a better position to bear risk, bears all the risk but in which effort can only be sustained through expenditures on supervision. This new view (Stiglitz, 1974) turns the traditional criticism of sharecropping on its head: it is precisely because of its incentive properties, relative to the relevant alternative, the wage system, that the sharecropping system is employed.

The contention that the rental system provides correct incentives is, however, not quite correct. The rental system provides correct incentives for effort decisions. But tenants make many decisions other than those involving effort; they make decisions concerning the choice of technique, the use of fertilizer, the timing of harvest, etc. These decisions affect the riskiness of the outcomes. For instance, many of the highyielding seed varieties have a higher mean output, but a greater sensitivity to rainfall. Whenever there is a finite probability of default (that is, the tenant not paying the promised rent). then tenants may not have, with the rental system, the correct incentives with respect to these decisions. Of course, with unlimited liability, the worker could be made to bear all of the costs. But since the tenant might be unable to pay his rent even if he had undertaken all of the "right" decisions, and since it is often difficult to ascertain whether the individual took "unnecessary" risks, most societies are reluctant to grant unlimited liability, or to use extreme measures like debtor prisons, to ensure that individuals do not take unnecessary risks. ${ }^{3}$ Hence, in effect, part of the costs of risk taking by the tenant is borne by the landlord." With sharecropping, both the landlord and the tenant face the same risks. ${ }^{5}$

Thus, sharecropping can be viewed as an institution which has developed in response to (a) risk aversion on the part of workers; (b) the limited ability (or desire) to force the tenant to pay back rents when he is clearly unable to do so; and (c) the limited ability to monitor the actions of the tenant (or the high costs of doing so).

The general theory has been extended in a number of directions, only three of which I can discuss here: cost sharing, interlinkage, and technical change.

In many situations, there are other important inputs besides labor and land, such as bullocks or fertilizer. How should these inputs be paid for? Clearly, if the worker pays all of the costs, 
but receives only a fraction of the benefits, he will have an insufficient incentive to supply these other inputs. Cost sharing is a proposed remedy. If the worker receives $50 \%$ of the output, and pays $50 \%$ of the cost, it would appear that he has the correct incentives: both benefits and costs have been cut in half. ${ }^{6}$

But in fact, though cost shares equal to output shares are common, they are far from universal. How do we explain these deviations from what seems both a simple, reasonable rule, and a rule which ensures economic efficiency? To find the answer, we again return to our general theoretical framework, which focuses on the role of imperfect information. First, it is clear that the landlord may want the tenant to supply more fertilizer than he would with a $50-50$ rule, if increasing the fertilizer increases the marginal product of labor, and thus induces the worker to work harder. Remember, the central problem of the landlord is that he cannot directly control the actions of his worker; he must induce them to work hard. The reason that sharecropping was employed was to provide these additional incentives.

But if a cost-sharing arrangement can be implemented, it means that the expenditures can be monitored; and if the expenditures can be monitored, there is no necessity for engaging in cost sharing; rather the terms of the contract could simply specify the levels of various inputs. But workers typically have more information about current circumstances than the landlord (in the fashionable technical jargon, we say there is an asymmetry of information). A contract which specifies the level of inputs cannot adapt to the changing circumstances. Cost-sharing contracts provide the ability and incentives for these adaptations, and thus are more efficient contracts than contracts which simply specified the level of inputs.?

Another aspect of economic organization in many LDCs is the interlinkage of markets: the landlord may also supply credit (and he may also supply food and inputs as well). How can we explain this interlinkage? Some have claimed that it is simply another way that landlords exploit their workers. We shall comment later on these alternative explanations. For now, we simply note that our general theory can explain the prevalence of interlinkage (both under competitive and noncompetitive circumstances). We have repeatedly noted the problem of the landlord in inducing the worker both to work hard and to make the "correct" decisions from his point of view (with respect to choice of technique, etc.) Exactly analogous problems arise with respect to lenders. Their concern is that the borrower will default on the loan. The probability of a default depends in part on the actions taken by the borrower. The actions of the tenant-borrower thus affect both the lender and the landlord. Note too that the terms of the contract with the landlord will affect the lender, and vice versa: if the landlord can, for instance reduce the probability of default by supplying more fertilizer, the lender is better off. The actions of the borrower (both with respect to effort and the choice of technique) may be effected by the individual's indebtedness, so that the landlords (expected) income may be affected by the amount (and terms) of indebtedness. There appear to be clear and possibly significant externalities betwen the actions of the landlord and the actions of the lender. Whenever there are such externalities, a natural market solution is to internalize the externality, and that is precisely what the interlinkage of markets does. ${ }^{8}$

Thus, interlinkage is motivated by the desire for economic efficiency, not necessarily by the desire for further exploitation of the worker.

Interlinkage has, in turn, been linked to the incentives landlords have for resisting profitable innovations. Bhaduri ${ }^{9}$ has argued, for instance, that landlords-cum-creditors may resist innovations, because innovations reduce the demand for credit, and thus the income which they receive in their capacity as creditors. Braverman and Stiglitz ${ }^{10}$ have shown that there is no presumption that innovations result in a reduction in the demand for credit. Credit is used to smooth income across periods, and under quite plausible conditions, innovations may either increase or decrease the aggregate demand for credit. But they argue further that what happens to the demand for credit is beside the point.

The central question is simply whether the innovation moves the economically relevant utilities possibilities schedule outward or inward. The utilities possibilities schedule gives the maximum level of (expected) utility to one group (the landlord) given the level of (expected) utility of the other (the workers). The economically relevant utilities possibilities curve takes into account the information problems which have been the center of our discussion thus far, for instance, the fact that with sharecropping, individuals' incentives are different from what they would be with costless monitoring. The utilities possibilities schedule with costless monitoring might move one way, the economically relevant utilities possibilities schedule the other. Thus, for instance, there are innovations which, at each level of input, increase the output, but which, at the same time, exacerbate the incentives-monitoring problem. Such innovations would not be socially 
desirable. Landlords would resist such innovations, as well they should, though from an "engineering" point of view, such innovations might look desirable.

The consequences of interlinkage for the adoption of innovations, within this perspective, are ambiguous. There are innovations which would be adopted with interlinkage, but would not without it, and conversely; but the effect of the innovation on the demand for credit does not seem to play a central role.

Though the landlord correctly worries about the incentive-monitoring consequences of an innovation, one should not jump to the conclusions either that the landlords collectively make decisions which maximize their own welfare, or that the landlord always makes the socially efficient decision. The landlord, within a competitive environment, will adopt an innovation if at current prices (terms of contracts, etc.) it is profitable for him to do so. Of course, when all the landlords adopt the innovation, prices (terms of contracts) will change, and they may change in such a way that landlords are adversely affected. "In a competitive environment landlords cannot resist innovations simply because it is disadvantageous to them to do so. (By contrast. if they are in a "monopoly" position. they will not wish to resist such innovations, since presumably they will be able to capture all the surplus associated with the innovation.)

But just as the market allocation is not constrained Pareto efficient (even assuming a perfectly competitive economy) whenever there are problems of moral hazard, so too the market decisions concerning innovation are not constrained Pareto efficient. (We use the term constrained Pareto efficient to remind us that we are accounting for the limitations on information; we have not assumed the government has any information other than that possessed by private individuals.) Though in principle there exist government interventions which (accounting for the costs of information) could make everyone better off, whether such Pareto improving interventions are likely to emerge from the political process remains a moot question.

\section{ALTERNATIVE TIEORIES}

In this section, I wish to present in summary form what I vicw to be the major competing approaches to understanding the organization of economic activity in the rural sector.

In many respects, I see my view as lying between other more extreme views. In one, the peasant is viewed as rational, working in an environment with reasonably complete information and complete and competitive markets. In this view, then, the differences between LDCs and more developed countries lies not so much in the difference between sophisticated, maximizing farmers and uneducated rule-bound peasants, as it does in differences in the economic environments, the goods produced by these economies, their endowments, and how their endowments are used to produce goods. In this view, sharecropping is a rational response to the problems of risk sharing; but there is less concern about the incentive problems than I have expressed; with perfect information and perfect enforceability of contracts, the sharecropping contract can enforce the desired level of labor supply and the choice of technique which is efficient. These theories have had little to say about some of the other phenomena which I have discussed: interlinkage, technical change, cost sharing. Interlinkage might be explained in terms of the advantages in transactions costs, but if transactions costs were central, one should only have observed simple cost-sharing rules (with cost share equalling output share).

By contrast, there are those who view the peasant as irrational, with his behavior dictated by customs and institutions which may have served a useful function at some previous time but no longer do so. This approach (which I shall refer to, somewhat loosely, as the institutionalhistorical approach) may attempt to describe the kinds of LDCs in which there is sharecropping, interlinkage, or cost sharing. It may attempt to relate current practices to earlier practices. In particular, the institutional-historical approach may identify particular historical events which lead to the establishment of the sharecropping system, or to the development of the credit system. But this leaves largely unanswered the question of why so many LDCs developed similat institutional structures, or why in some countries cost shares equal output shares, while in others the two differ. More fundamentally, a theory must explain how carlier practices devcloped; and to provide an explanation of these, one has to have recourse to one of the other theorics. Thus, by itself, the institutional-historical approach is incomplete.

Still a third view emphasizes the departures from competitiveness in the rural sector, and the consequent ability of the landlords to exploit the workers. In some cases, workers are tied to their land; legal constraints may put the landlord in a position to exploit the worker. But in the absence of these legal constraints, one has to explain how the landlords exercise their allegedly coercive powers. In many LDCs there is a well-developed 
labor market. Many landlords need laborers at harvest time and at planting time. The worker chooses for whom he will work. It is important to recognize that the exploitation hypothesis fails to explain the mechanisms by which, in situations where there are many landlords, they exercise their exploitative power. ${ }^{13}$ More generally, it fails to explain variations in the degree of exploitation over time and across countries. The fact that wages are low is not necessarily evidence of exploitation: the competitive market will yield low wages when the value of the marginal product of labor is low.

The exploitation hypothesis also fails to explain the detailed structure of rural organization: why cost shares are the way they are, or why (or how) landlords who can exploit their workers use the credit market to gain further exploitative capacity.

There may be some grain of truth in all these approaches. Important instances of currently dysfunctional insitutions and customs can clearly be identified. Institutional structures clearly do not adapt instantaneously to changed circumstances. Yet, as social scientists, our objective is to identify the systematical components, the regularities of social behavior, to look for general principles underlying a variety of phenomena. It is useful to describe the institutions found in the rural sector of LDCs, but description is not enough.

Therefore, I view the rationality hypothesis as a convenient starting point, a simple and general principle with which to understand economic behavior. Important instances of departures from rationality may well be observed. As social scientists, our objectives is to look for systematic departures. Some systematic departures have been noted, for instance in the work of Tversky, in individuals' judgments of probabilities, particularly of small probability events; but as Binswanger's 1978 study has noted, departures from the theory appear less important in "important" decisions than in less important decisions. Many of the seeming departures from "rationality" that have been noted can be interpreted as "rational" decision-making in the presence of imperfect information.

I also view the competitiveness hypothesis as a convenient starting point. ${ }^{13}$ Many of the central phenomena of interest can be explained without recourse to the exploitation hypothesis. Some degree of imperfect competition is not inconsistent with the imperfect information paradigm: the imperfect information paradigm provides part of the explanation for the absence of perfect competition; it can help identify situations where the landlords may be in a better position to exploit the workers. Moreover, to the extent that imperfect information limits the extent to which even a monopoly landlord can extract surplus from his workers, the imperfect information paradigm can provide insights into how he can increase his monopoly profits. The theory of interlinkage we have developed can thus be applied to the behavior of a monopolist landlord.

There is one other approach that has received some attention that is, in fact, closely related to the one I have advocated: the transactions cost approach, which attempts to explicate economic relations by focusing on transactions costs. Information costs are an important part of transactions costs (though information problems arise in other contexts as well). My reservations concerning the transactions cost approach lie in its lack of specificity: while the information paradigm provides a well-defined structure which allows one to derive clear propositions concerning, for instance, the design of contracts, the transactions cost paradigm does not. Thus, the transactions cost approach might provide some insight into why cost sharing is employed, but not into the terms of the cost-sharing agreement. The transactions cost paradigm might say that economies of scope provide an explanation for why the landlord also supplies credit, but it does not provide insights into when the landlord-cumcreditor would subsidize credit, or when he would "tax" it. Moreover, while the information paradigm identifies parameters which affect the magnitude of the externalities between landlords and creditors, and thus enables, in principle, the identification of circumstances under which interlinkage is more likely to be observed; the transactions cost paradigm can do little more than to say that there are circumstances in which the diseconomies of scope exceed the economies, and in these circumstances there will not be interlinkage.

\section{CRITERIA FOR EVALUATING ALTERNATIVE THEORIES}

In the previous section, I discussed briefly some of the major competing hypotheses. In this section, I wish to outline a set of criteria for evaluating a theory, and to apply these criteria to these alternative theories. No novelty is claimed for the criteria; no attempt is made to provide a general epistemological theory. ${ }^{14}$ These are presented more in the spirit of a "working man's" criteria.

We can divide the criteria into two groups: 
internal and external. The internal criteria include: ${ }^{15}$

(a) Internal consistency: Are the axioms (underlying assumptions) mutually consistent, and do the conclusions follow from these assumptions?

(b) Simplicity: In general, the fewer the assumptions required to explain the given phenomena, the better.

(c) Completeness: The assumptions of the model should be as "primitive" as possible.

Thus, in macroeconomics, a theory which explains unemployment in terms of wage rigidities is, in this sense, incomplete: it leaves open the question of why wages are rigid.

The external criteria include:

(a) Verifiability (or falsifiability): The theory should have at least some implications which are verifiable or falsifiable, in principle; that is, it should at least be possible to design thought experiments under which some of the implications of the theory could be rejected. (b) External consistency: Are all the implications of the model consistent with observations? Note that among the (obvious and direct) implications of the model are those that directly follow from the assumptions; thus, if an assumption itself can be falsified, the model will not possess the property of external consistency. Friedman's contention that a theory should only be judged by the validity of its conclusions is, in this view, wrong. Theories whose assumptions seem unreasonable, i.e., whose assumptions themselves can be falsified or whose assumptions have other implications which seem unacceptable (i.e., can be falsified) should be rejected. Some of the implications of many "bad" theories may be correct; indeed, probably no theory that has received any attention has all of its implications inconsistent with (at least some interpretations of) the data. But a good theory should have no implication which is inconsistent with observations.

(c) External completeness: The theory should have something to say about as many regularities that have been observed in the area of study as possible. Thus, a theory which explains both why there is sharecropping as well as the determinants of the shares is better than a theory which simply explains why there is sharecropping. This is closely related to the criteria of:

(d) Specificity: A good theory should make as many specific predictions concerning particular phenomena as possible.

(e) Predictive power: A good theory should not only be consistent with regularities which have already been noted, but should suggest new regularities which have not yet been noted.

(f) Generality: The same general hypotheses should be able to explain phenomena in widely different contexts.

I now want to review the performance of the alternative theories in terms of these basic criteria. The imperfect information paradigm does well, I would argue, on all of the criteria. The work in this area has been marked by an attempt to state clearly the assumptions, and to derive its conclusions from the assumptions: it does well on the criterion of internal consistency. Similarly, it does well on the other two internal criteria: the assumptions are simple and are reasonably primitive. Though in most work, the information technology is taken as given, in some ongoing research (see e.g., Braverman-Stiglitz, forthcoming), even this is taken to be endogenously determined. The theory provides specific predictions which are verifiable, and indeed has something to say about virtually every aspect of rural economic organization. It makes predictions concerning a variety of regularities that should be found in LDCs, but unfortunately, these have not been subjected to rigorous testing. At the same time, there is no well-agreed upon regularity that seems inconsistent with the theory.

One of its most attractive properties, however, is that the information paradigm provides a general framework which is applicable to both developed and less developed economies. The concerns about effort and choice of technique which are central to sharecropping reappear, in somewhat modified form, in the analysis of labor and capital markets in more developed countries. It shares this property with the "rational peasant, with perfect markets and complete information" paradigm. But the latter theory fails to provide a good account of the differences between developed and less developed economies.

But my major objection to the rational peasant model with full information and complete markets (as with the corresponding theories of developed economies) is that it is inconsistent with many observations and it fails to provide explanations of others.

It does not explain why sharecropping is employed (with perfect information, there are a variety of equivalent contractual forms; if sharecropping were employed, the contract would specify the amount of labor to be supplied).

It fails to explain cost sharing, and in particu- 
lar why cost shares should differ from output shares.

It assumes that there is a complete set of risk markets; it is clear that individuals cannot purchase insurance against many important risks and that this has important consequences for their behavior.

In most small villages, it is not reasonable to assume that if a landlord offered a rupee less to his wage laborers, he would obtain no workers. In many situations, there appear to be workers who are willing to work at the going wage, but fail to obtain employment: there appears to be involuntary unemployment, a phenomenon which seems inconsistent with the classical competitive models.

This theory can be adapted to make it at least seem to explain the phenomena under study and to make it seem less inconsistent with the facts: ${ }^{16}$ indeed, our imperfect information paradigm can be thought of as one such adaptation. But we would argue that it is a fundamental alteration, one which effects our views of economic relations under a wide variety of circumstances. When a theory provides predictions which are inconsistent with the facts in a wide variety of circumstances, and when it fails to provide explanations of important regularities, what is needed is not an ad hoc modification of the model on a case-by-case basis, but rather a basic reformulation: the imperfect information paradigm provides such a reformulation.

The transactions cost approach represents another attempt to modify the basic theory in a consistent way. As we have commented above, information costs are a particular form of transaction costs, and I find many aspects of the transactions cost approach attractive. ${ }^{17}$ But the theory fails on several of the critical external criteria: to the extent that the theory relies on unobservable transaction costs, it often seems to fail the test of falsifiability; just as the present set of economic relations is justified by current (unobservable) transaction costs, changes in the nature of economic relations are "explained" by reference to similarly unobservable changes in transaction costs. The theory also fails the test of specificity of predictions and of external completeness: as we noted, while it may provide an explanation for why sharecropping is employed, it cannot explain the nature of the cost-sharing arrangements and has little to say about other terms of the sharecropping contract.

By contrast, the exploitation theory fails on both the internal and external criteria for judging theories. There is not a clearly stated set of primitive assumptions from which the conclusions logically follow. For instance, if the struc- ture of economic relations is determined by the attempt of landlords to exploit their workers, what determines the limits on their capacities to do so? The theory fails to explain why sharecropping provides a better method of exploitation than other forms of contractual arrangements; it fails to explain why cost sharing enhances the ability of the landlord to exploit his workers. It fails to explain the circumstances under which cost shares would exceed output shares. And it fails to explain why providing credit enhances the ability of the landlord to exploit the peasant. When there are many landlords in a community, it fails to explain how they can act collusively together. The experience with cartels in other areas is that it is hard to maintain collusive arrangements voluntarily when the number of participants becomes more than a few. If this is true here, then the theory only provides an explanation of the structure of economic relations within communities with a limited number of landlords; if this is not true in LDCs, why?

To the extent that the theory relies on the notion of power which cannot be independently quantified, the theory is not falsifiable: one can always account for differences in the terms of the contract over time or geographically in terms of differences in power. ${ }^{\text {Po }}$ To the extent that the theory fails to provide answers to these questions, it is seriously incomplete.

\section{CONCLUSIONS}

The theory of rural organization which is based on rational peasants in environments in which information is imperfect and costly provides a simple explanation for a wide variety of phenomena in LDCs. It represents an important application of a more general paradigm, what I have referred loosely to as the "Imperfect Information Paradigm" which has been useful in explaining phenomena under a wide variety of settings, under competition, oligopoly, and monopoly, in labor markets, capital markets, insurance markets, and product markets. The richness of social phenomend is such as to make it unreasonable to expect any theory to explain all of the observed variations in institutions and behavior. But a theory should at least be able to explain the important regularities. Here, we are concerned with explaining sharecropping, both its widespread use, and the form it takes; it should explain cost sharing, with cost shares frequently differing from outpul shares, and the interlinkage of credit and land markets. This our theory does, and the compet- 
ing theories fail to do. There is a rich set of further predictions emanating from our theory which have yet to be tested. Whether, when these tests are performed, the theory will still stand, or whether it will have to be modified, or abandoned, remains to be seen.

\section{NOTES}

1. For two surveys of certain aspects of this work. see Stiglitz (1982b, 1985).

\section{See Stiglitz (1974).}

3. Indeed, such extreme measures may have deleterious incentive effects, discouraging risk taking.

\section{See Johnson (1950); Allen (1985).}

5. This aspect of sharecropping has been emphasized by Johnson (1950), and by Braverman and Stiglitz (1982a). See also Stiglitz and Weiss (1981).

6. See Heady (1947).

7. See Braverman and Stiglitz (1982b).

8. See Braverman and Stiglitz (1982a). This problem is discussed in the more general information theoretic literature under the rubric of the multiple principleagent problem. The externalities which we have discussed here arise in virtually all moral hazard problems. See Arnott and Stiglitz (1984).

9. See Bhaduri (1973).

10. Braverman and Stiglitz (forthcoming).

11. If the innovation, at the current prices, increases the demand for workers enough, then the terms of the contracts may shift sufficiently in workers favor to make landlords worse off. This is analogous to what, in more simple contexts. is referred to as a Pigou land-saving innovation.

12. Note that recent advances in repeated games have shown how collusive outcomes can be attained even in non-cooperative settings. Thus, landlords in rural economies where mobility is limited and in which there are only a few landlords in any community may well act collusively. The circumstances in which these noncooperative collusive arrangements work well has. however, not been well studied.

13. Indeed, with limited labor mobility. in small villages the labor markets are unlikely to be perfectly competitive; at the same time, the landlord is far from a labor monopolist. The real world is probably better described by a model of "monopolistic competition" than either of the polar models, monopoly or perfect competition.

14. Similarly, this is not the place to provide an evaluation of alternative theories (e.g., the theories of Karl Popper).

15. This list is not meant to be exhaustive. An important criterion in other contexts is robustmess; the conclusions of the theory should not be sensitive to small perturbations in the assumptions.

16. When the theory gets complicated by these ad hoc modifications it loses the property of simplicity, which was originally one of its main virtues.

17. It is sometimes suggested that, once transactions costs are accounted for, equilibrium with rational peasants will have all the standard efficiency properties that economies with no transactions costs have. This is another example where the conclusion does not follow logically from the assumptions; the conclusion is arrived at by reasoning by analogy. Transactions costs (including information costs) are "like" other production costs. Why, once these are appropriately accounted for, should not the economy still be efficient?

Unfortunately, it turns out that, in general, economies with imperfect information (or incomplete markets) are not constrained Pareto efficient (where the term "constrained" Pareto efficient simply reminds us that we have appropriately taken into account the transactions costs (information imperfection, incomplete markets). (See Greenwald and Stiglitz, forthcoming.) The formalization of Adam Smith's invisible hand conjecture is one of the great achievements of modern economic theory; the Fundamental theorem of economics, like any other theorem, depends on the assumptions. The assumptions concerning perfect information. no transactions costs, and complete market markets are not innocuous assumptions. but are central to the validity of the result. Information costs may, in some respects, be like other costs of production, but the differences are sufficicntly important to invalidate the Fundamental Theorem of Welfare Economics.

18. Thus, "power" is to the exploitation theory what transactions cost is to the transactions cost model.

\section{REFERENCES}

Allen, F., "The fixed nature of sharecropping contracts," Journal of Public Economics (March 1985). pp. $30-48$.
Arnott, R., and J. E. Stiglitz, "Equilibrium in competitive insurance markets," Mimeo. (Princeton University, 1984). 
Bhaduri, A., "Agricultural backwardness under semifeudalism," Economic Journal (1973).

Binswanger, H. P., "Attitudes towards risk: Experimental measurement evidence in rural India," American Journal of Agricultural Economics, Vol. 62, No. 3 (August 1980), pp. 395-407.

Binswanger, H. P., "Attitudes towards risk: Implications and psychological theorias of an expcriment in rural India," Yale University Economic Growth Center DP 286 (1978b).

Braverman, A., and J. E. Stiglitz, "Sharccropping and the interlinking of agrarian markets," American Economic Review, Vol. 72, No. 4 (September 1982a), pp. 695-715.

Braverman, A., and J. E. Stiglitz, "Moral hazard, incentive flexibility and risk: Cost sharing arrangcments under sharecropping," / Princeton University, Econometric Research Center Memorandum No. 298 (1982b).

Braverman, A., and J. E. Stiglitz, "Cost sharing arrangements under sharecropping: Moral hazard, incentive flexibility and risk," Mimeo. (Princeton University, 1985).

Braverman, A., and J. E. Stiglitz, "Landlords, tenants and technological innovations," Journal of Development Economics (forthcoming).

Greenwald, B., and J. E. Stiglitz, "Externalities in economies with imperfect information and incomplete markets," Quarterly Journal of Economics, (forthcoming).

Heady, E., "Economics of farm leasing system," Journal of Farm Economics (August 1947).

Johnson, D. Gale "Resource allocation under share contracts," Journal of Public Economics (April 1950), pp. 111-123.

Newbery, D., and J. E. Stiglitz, "Sharecropping, risk sharing, and the importance of imperfect information," paper presented to a conference in Mexico City, March 1976 and published in J. A. Roumasset et al. (Eds.), Risk, Uncertainty and Development (SEARCA, A/D/C, 1979), pp. 311-341.

Newbery, D., and J. E. Stiglitz, The Theory of Commodity Price Stabilization (Oxford University Press, 1981).

Newbery, D., and J. E. Stiglit7, "The choice of techniques and the optimality of market equilibrium with rational expectations," Journal of Political
Economy, Vol. 90, No. 2 (April 1982), pp. 223-246.

Stiglitz, J. E., "Rural-urban migration, surplus labor and the relationship between urban and rural wages," East African Economic Review, Vol. 1-2 (December 1969), pp. 1-27.

Stiglitz, J. E., "Alternate theories of wage determination and unemployment in LDCs: The labor turnover model," Quarterly Journal of Economics, Vol. 87 (May 1974), pp. 194-227.

Stiglitz, J. E., "Incentives and risk sharing in sharecropping," Review of Economic Studies, Vol. 41 (April 1974), pp. 219-255.

Stiglitz, J. E., "The efficiency wage hypothesis, surplus labor and the distribution of income in LDCs," Oxford Economic Papers, Vol. 28, No. 2 (July 1976), pp. 185-207.

Stiglitz, J. E., "Some further remarks on cost-benefit analysis," in H. Schwartz and R. Berney (Eds.), Social and Economic Dimensions of Project Evaluation (IDB, 1977); Proceedings of the Symposium on Cost-Benefit Analysis, IDB, Washington, D.C., March 1973, pp. 253-282.

Stiglitz, J. E., "Alternative theories of wage determination and uncmployment: The efficiency wage model," in Gersovitz et al., (Eds.) The Theory and Experience of Economic Development: Essays in Honor of Sir W. Arthur Lewis (London: George Allen \& Unwin, 1982a), pp. 78-106.

Stiglitz, J. E., "Structure of labor markets and shadow prices in L.DCs," presented at World Bank Conference, February 1976, in R. Sabot, (Ed.) Migration and the Labor Market in Developing Countries (Boulder, CO: Westview Press 1982b), pp. 13-64.

Stiglitz, J. E., "The wage-productivity hypothesis: Its economic consequences and policy implications," paper presented to the American Economic Association (1982).

Stiglitz, J. E.. "Economies of information and the theory of economic development," Revista de Econometria (forthcoming).

Stiglicz, J. E., and A. Weiss, "Credit rationing in markets with imperfect information," American Economic Review, Vol. 71, No. 3 (June 1981), pp. $39.3-410$.

l'versky, A., "Intransitivity of preferences," Psychological Review, Vol. 76 (1969), pp. 31-48. 